\title{
The impact of gas slug flow on microfiltration performance in an airlift external loop tubular membrane reactor
}

\author{
Yun Wu, ${ }^{\text {abc }}$ Jie Wang, ${ }^{\text {ab }}$ Hongwei Zhang, ${ }^{\text {ab }}$ Huu Hao Ngo, ${ }^{\mathrm{c}}$ Wenshan Guo ${ }^{\mathrm{c}}$ and Nan Zhang ${ }^{\mathrm{d}}$ \\ ${ }^{a}$ State Key Laboratory of Separation Membranes and Membrane Processes, Tianjin Polytechnic \\ University, Tianjin 300387, China.E-mail:wucloud@163.com \\ ${ }^{b}$ School of Environmental and Chemical Engineering, Tianjin Polytechnic University, Tianjin \\ 300387, China \\ ${ }^{c}$ School of Civil and Environmental Engineering, University of Technology Sydney, Broadway, \\ NSW 2007, Australia \\ ${ }^{d}$ CNOOC Tianjin Chemical Research and Design Institute, Tianjin 300387, China
}

\begin{abstract}
This work investigated the impact of gas slug flow on microfiltration in an airlift external loop tubular membrane reactor. A complete description for the characteristics of the slug flow was obtained as the aeration rate increased from 30 to $120 \mathrm{~L} \mathrm{~h}^{-1}$ with an interval of $30 \mathrm{~L} \mathrm{~h}^{-1}$. The shear stress of the falling film region could reach $6.37 \times 10^{-3} \mathrm{~Pa}$ with the aeration rate of $90 \mathrm{~L} \mathrm{~h}^{-1}$. Experimental results showed that the growth of transmembrane pressure (TMP) could be controlled effectively by increasing the aeration rate and the optimal aeration rate in a slug flow was around $90 \mathrm{~L} \mathrm{~h}^{-1}$. However, a subsequent increase in the aeration rate had no significant effect on slowing down the TMP growth rate. Turning the constant air-flow into periodic pulsatile airflow, low gas-velocity and high gas-velocity led to alternate operation in filtration. When the alternate interval of pulsatile air-flow was $60 \mathrm{~s}$ at the alternate aeration rates of $30 / 90 \mathrm{~L} \mathrm{~h}^{-1}$ and $60 / 90 \mathrm{~L} \mathrm{~h}^{-1}$, it could delay membrane fouling and save a lot of gas compared with implementing a constant air-flow of $90 \mathrm{~L} \mathrm{~h}^{-1}$. Finally, for different water outlet positions along the membrane tube, membrane fouling gradually slowed down from the bottom to the top.
\end{abstract}

\section{Introduction}

A tubular membrane reactor features many advantages, such as wide flow channels, easy automation and freedom from clogging, which make it very efficient for high solid content solution separation, oil-water separation, etc. However, the application of a tubular membrane is still limited by membrane fouling, which results in a decrease in permeate flux. To reduce the membrane fouling rate in the separation and improve filtration efficiency, a high cross-flow velocity is required near the membrane surface. It will lead to much energy consumption. ${ }^{1}$ It has been documented that air sparging, which generates a gas-liquid two-phase flow, is an efficient technique to decrease the energy consumption in airlift membrane reactors. ${ }^{2-4}$ It is a new type of reactor established on the basis of membrane reactors and airlift reactors. Generally, airlift reactors are classified into two categories, internal loop airlift reactor (ILAR) and external loop airlift reactor (ELAR). ELARs have been widely applied in chemical, biological, and water treatment industries due to their simple construction, low power consumption and good mixing effectiveness. Meanwhile, they are efficient in reducing membrane fouling by inducing flow 
circulation. ${ }^{5,6}$ For this reason, the external loop airlift tubular membrane reactor was employed in this study.

Gas-liquid two-phase flow as well as other techniques such as pulsatile flow, turbulence promoter, secondary flow, etc., has been developed to decrease concentration polarization and membrane fouling. ${ }^{2,7-9}$ Vera et al. used gas-liquid two-phase flow in inorganic tubular membrane to strengthen the cross-flow microfiltration process when filtering ferric hydroxide suspension and biological treatment wastewater, and found that the permeate flux increased significantly as the slug flow formed in the tube. ${ }^{10}$ Zhang et al. investigated air sparging for flux enhancement of a synthetic wastewater filtration at different gas-flow rates, biomass concentrations and suction pressures in an external-loop airlift ceramic membrane bioreactor. They all proved that air sparging could significantly reduce the cake layer's thickness and slow down the rate of membrane fouling effectively. ${ }^{11}$ Slug flow is a type of gas-liquid two-phase flow. It was reported that in a gas-liquid two-phase cross-flow microfiltration process, slug flow was the most favorable flow pattern for enhancing the filtration process in many studies. ${ }^{12-14}$

For a microfiltration at the slug flow, gas slug and liquid slug caused different turbulence intensities and shear stresses on the membrane surface. ${ }^{15}$ The membrane surface was alternately exposed to positive and negative shear stresses at slug flow. The successive and unstable stresses were expected to prevent filtered particles from depositing on the membrane surface and then enhance the filtration mass transfer.16 Many studies have shown that slug flow can slow down the rate of membrane fouling effectively. However, a further increase in the aeration rate had no significant effect on it. Pulsatile air-flow is a new effective method of slow down the rate of membrane fouling and gradually attracts more attention from researchers. In the early years, pulsatile flow was often used for improving convective heat transfer in corrugated tube. In the study of Wang et al., ${ }^{17}$ the numerical results indicate that the pulsating flow increases the heat transfer efficiency of the corrugated tube flow by $90 \%$ compared to the constant flow. Heat transfer enhancement of pulsating flow is due to the pulsating flow which makes corrugated tube generate whirlpools and increase disturbance and reduce the thermal boundary layer thickness. To date, research which applies to pulsatile air-flow in microfiltration is relatively less. Therefore, this paper investigates the influence of growth rate of TMP when constant air-flow turns into pulsatile air-flow. Such a change can not only save a lot of gas but also slow down the rate of membrane fouling, which makes this analysis significant.

The hydrodynamics of gas-liquid two-phase flow have been characterized by Collins and Bendiksen in vertical tubes. ${ }^{18,19}$ Zhang et al. characterized some relevant hydrodynamic parameters in an airlift ceramic membrane reactor to identify their effects on steady state permeate flux in the case of slug flow. ${ }^{20}$ The electrochemical real time measurement system was used in this paper to monitor slug flow hydraulics parameters. After that, the pulsatile air-flow's characteristics and their effects on the performance of this system were evaluated to reduce membrane fouling and enable additional energy saving. Finally, analyze the membrane fouling status of four water outlets from bottom to the top along the membrane tube. In general, tubular membrane application is limited by membrane fouling, so effectively slowing down the rate of membrane fouling is very important for expanding the use of the tubular membrane. 


\section{Model development}

These equation main analyse the Taylor bubble in the full development of the slug flow. In the piston flows system, the total superficial velocity is equal at an arbitrary cross-section of the horizontal position. ${ }^{21}$ As shown in Fig. 1, gas slug regime consists of Taylor bubbles and falling film region, the superficial gas-velocity and the superficial liquid velocity at $\mathrm{Y}-\mathrm{Y}$ cross-section can be expressed as the following relationship (due to the velocity being a vector, $U_{L}^{Y}$ is negative):

$$
U=U_{\mathrm{G}}+U_{\mathrm{L}}=U_{\mathrm{G}}^{\mathrm{Y}}+\mathrm{U}_{\mathrm{L}}^{\mathrm{Y}}
$$

and at $\mathrm{Y}-\mathrm{Y}$ cross-section:

$$
\left(\frac{\pi}{4}\right) d^{2} U_{\mathrm{G}}^{\mathrm{Y}}=\left(\frac{\pi}{4}\right)\left(d-2 \delta_{\mathrm{F}}\right)^{2} U_{\mathrm{B}}
$$

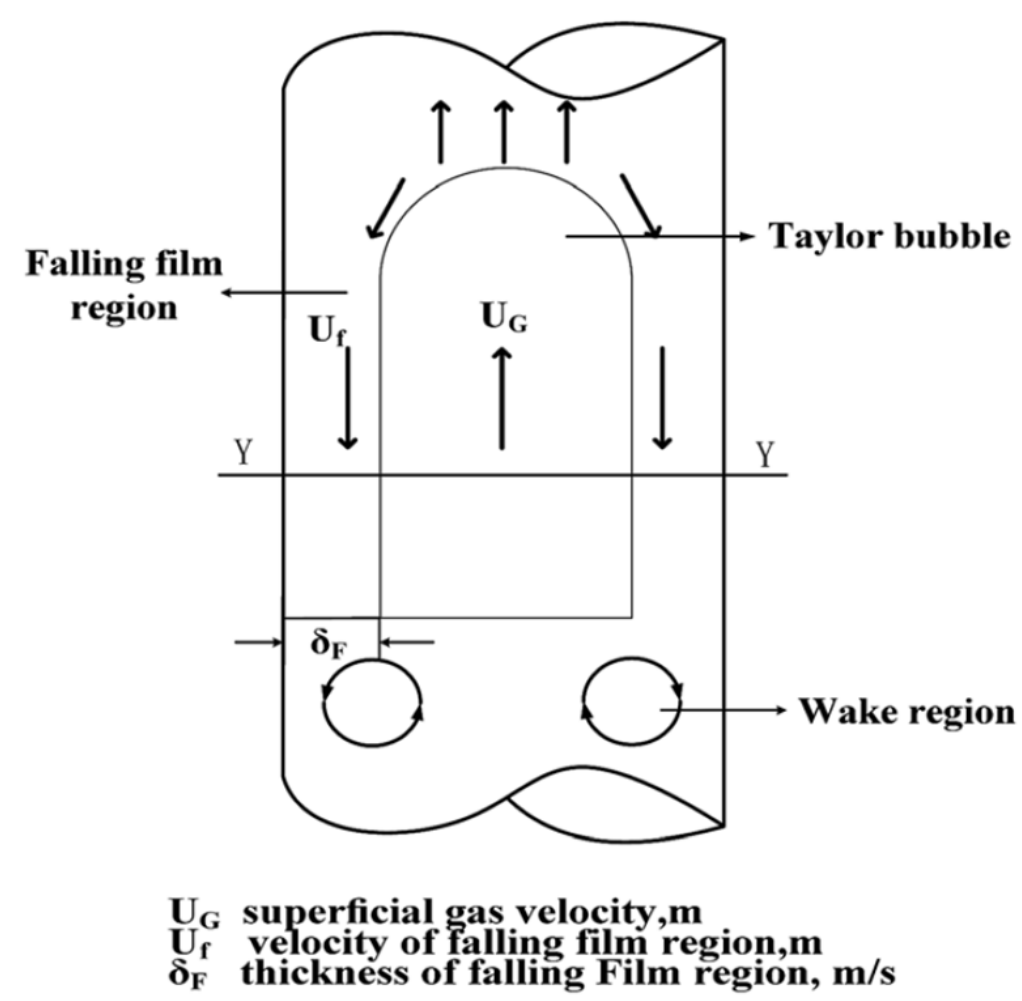

Fig. 1 Structure of gas slug regime.

Eqn (3) below was used to calculate the average thickness of falling film region $\delta_{\mathrm{F}}:{ }^{22}$

$$
\delta_{\mathrm{F}}=0.063\left[\mathrm{U}_{\mathrm{L}}^{\mathrm{Y}} /(\mathrm{gd})^{0.5}\right]^{2 / 3} d
$$

By incorporating eqn (1)-(3), $U_{\mathrm{L}}^{\mathrm{Y}} U_{\mathrm{G}}^{\mathrm{Y}}$ and $\delta_{\mathrm{F}}$ can be obtained. Where $U$ is the total superficial velocity, $\mathrm{m} \mathrm{s}^{-1}, U_{\mathrm{G}}^{\mathrm{Y}}, U_{\mathrm{L}}^{\mathrm{Y}}$ are the superficial gas and liquid velocities at cross-section $\mathrm{Y}, \mathrm{m} \mathrm{s}^{-1}, U_{\mathrm{B}}$ is the bubble velocity, $\mathrm{m} \mathrm{s}^{-1}$, obtained by the experiment, $d$ is the inner diameter of tubular membrane, $\mathrm{m}, \mathrm{g}$ is acceleration due to gravity, $\mathrm{m} \mathrm{s}^{-2}$. 
The average velocity of falling film region $U_{\mathrm{f}}\left(\mathrm{m} \mathrm{s}^{-1}\right)$ can be described as:

$$
U_{\mathrm{f}}=\left(\frac{\pi}{4}\right) U_{\mathrm{L}}^{\mathrm{Y}} d^{2} /\left(\frac{\pi}{4}\right)\left[d^{2}-\left(d-2 \delta_{\mathrm{F}}\right)^{2}\right]=U_{\mathrm{L}}^{\mathrm{Y}} d^{2} /\left(4 d \delta_{\mathrm{F}}-4 \delta_{\mathrm{F}}^{2}\right)
$$

The wake's length $(m)$ and the Reynolds number of the wake region of gas slug of fall film ${ }^{23}$ can be expressed as eqn (5) and (6):

$$
\begin{gathered}
L_{\mathrm{W}}=\left(0.3+1.4 \times 10^{-2} \mathrm{Re}\right) d \\
\operatorname{Re}=\left(U_{\mathrm{B}}-U_{\mathrm{G}}\right) d / 4 u
\end{gathered}
$$

where $u$ is the kinematic viscosity, $\mathrm{m}^{2} \mathrm{~s}^{-1}$.

The shear stress of the film flow around the bubble $(\mathrm{Pa})$ can be presented by the following relationship ${ }^{24}$ as eqn (7)

$$
\tau_{\mathrm{f}}=\frac{1}{8} f_{\mathrm{L}} \rho_{\mathrm{L}} U_{\mathrm{L}}^{\mathrm{Y} 2}
$$

where $f_{\mathrm{L}}$ is the friction factor, $\rho_{\mathrm{L}}$ is the liquid density, $\mathrm{kg} \mathrm{m}^{-3}$. The friction factor is then obtained by one of the following relationships:

$$
\begin{gathered}
f_{\mathrm{L}}=64 / \mathrm{Re} \text { for laminar flow } \\
f_{\mathrm{L}}=0.3164 / \mathrm{Re}^{0.25} \text { for turbulence flow }
\end{gathered}
$$

\section{Experimental apparatus and materials}

\subsection{Airlift tubular membrane system}

The experimental set-up is illustrated in Fig. 2. A vertical glass tube (volume $10 \mathrm{~L}$, inner diameter $0.08 \mathrm{~m}$, length $2.00 \mathrm{~m}$ ) was used as the main body of the reactor. The filtration unit consisted of two identical single-tube tubular membranes with an intermediate glass tube connecting them. For the tubular membrane part, the single-tube tubular membrane (inner diameter $0.012 \mathrm{~m}$, length $0.60 \mathrm{~m}$, polyvinylidene difluoride (PVDF) membrane with an average pore size of $0.22 \mu \mathrm{m}$ ) with a filtration area of $0.0226 \mathrm{~m}^{2}$ had two water outlets at each end. The intermediate transparent glass tube (inner diameter $0.012 \mathrm{~m}$, length $0.40 \mathrm{~m}$ ) served to observe the flow pattern and insert the probe. The two tubular membranes and the intermediate transparent glass tube had the same internal diameter, which helped to avoid affecting the forming process of gas-liquid two-phase flow. The probe was used to measure the rising velocity of the Taylor bubble through the data acquisition system (USB-FS1208, Measurement Computing ${ }^{\text {TM }}$, Hungary). ${ }^{25}$ In order to ensure accuracy of detection, only the probe's cutting-edge was exposed while other parts remained insulated; the probe's cutting-edge was electric conduction and located in the center of the glass tube. The yeast suspension (at a concentration of $1 \mathrm{~g} \mathrm{~L}^{-1}$ ) was used to simulate the filtrated 
medium because it had the following characteristics: good solubility and repeatability, narrow particle size distribution, and certain biological activities.

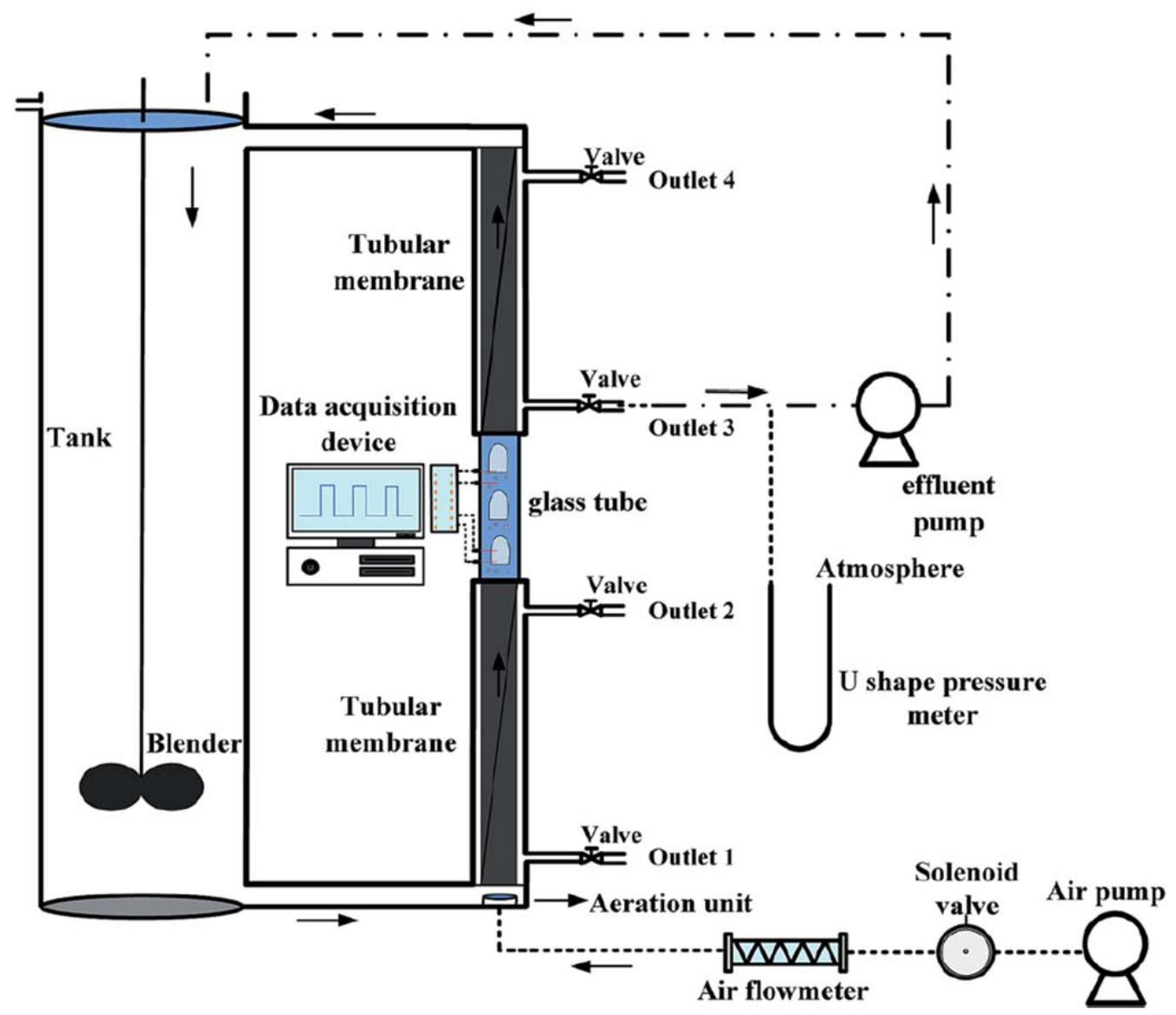

Fig. 2 Experimental diagram of the airlift tubular membrane system.

The solution was appropriate for analyzing the membrane filtration. ${ }^{26,27}$ Peristaltic pumps (BT100-2J, Baoding Langer Precision Pump Co., Ltd, China) were stabilized at $16 \mathrm{~mL} \mathrm{~min}{ }^{-1}$ with a flux of $45 \mathrm{~L} \mathrm{~m}^{-2} \mathrm{~h}^{-1}$ to ensure the constant flow for effluents remained constant. The solenoid valve was controlled through a timing switch to form a rectangular-wave pause, which was managed by a time relay. An aeration unit was placed at the bottom of the system. The airflow meter was used to control the air-flow. Membrane fouling was evaluated by the development of TMP over time. The TMP was measured by a U-shaped pressure meter that monitored membrane fouling.

During the operation, the permeate and the concentrate were recycled into the feed tank in order to maintain a constant feed concentration. Prior to all experiments being conducted, the membrane was chemically cleaned to achieve similar initial conditions for each test. The membrane was cleaned with sodium hypochloride for $3 \mathrm{~h}$ and tap water for $12 \mathrm{~h}$ with a high circulation flow rate of $2 \mathrm{~m} \mathrm{~s}^{-1}$. The temperature was kept at $20-22{ }^{\circ} \mathrm{C}$. 


\subsection{Testing principle}

Conductivity technology was implemented in this study. Four probes were divided into two groups installed on both ends of the intermediate transparent glass tube. Then two probes in each group were situated $0.05 \mathrm{~m}$ apart as the test electrode to detect the Taylor bubble and liquid slug's arrival. The voltage signal was recorded automatically every $1 \mathrm{~m} \mathrm{~s}^{-1}$ using the data acquisition system. When the probe's voltage signal dropped suddenly, this meant that the gas phase had arrived; if not, this was the liquid phase. Taking Fig. 3 as an example, according to the time lag $\Delta t_{\mathrm{B}}$ between the moments when one bubble passed through each probe and the distance between them, the rising velocity of the Taylor bubble can be calculated: $U_{\mathrm{B}}=0.05 / \Delta t_{\mathrm{B}}, \mathrm{m} \mathrm{s}^{-1}$, and then by the time the Taylor bubble passes through one probe $\Delta T_{\mathrm{B}}$, the bubble's length can be worked out: $L_{\mathrm{B}}=U_{\mathrm{B}} \times \Delta T_{\mathrm{B}}, \mathrm{m}$. This is the same method employed to calculate the length of liquid $L_{\mathrm{L}}$. The final results are equal to the average for a period of time in two groups. ${ }^{25}$

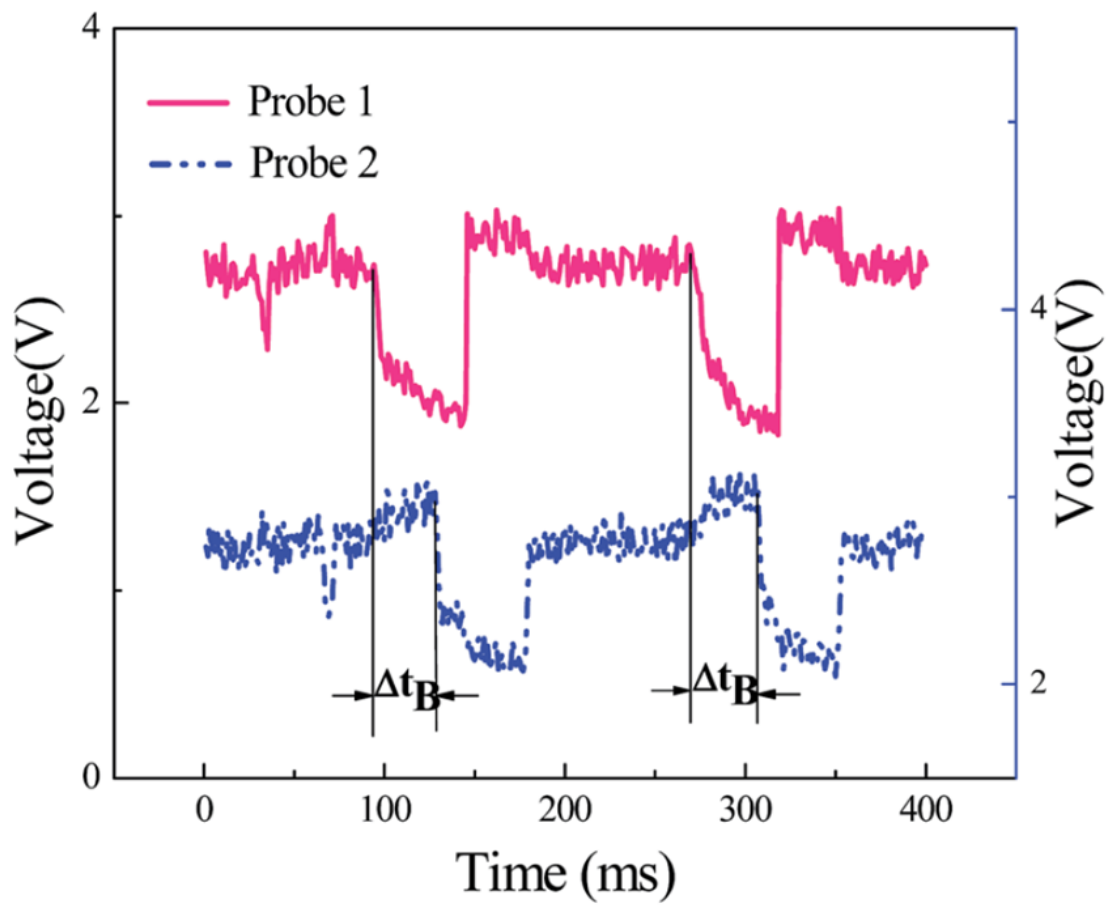

Fig. 3 Local voltage of two probes.

\section{Results and discussion}

\subsection{Effect of aeration rate on slug flow's hydrodynamic parameters and membrane fouling}

In this system, the experiment is divided into two groups, the one with no aeration, the one with aeration pipe was equipped for air sparging. For the experiment with aeration the aeration rates were modulated to $30 \mathrm{~L} \mathrm{~h}^{-1}, 60 \mathrm{~L} \mathrm{~h}^{-1}, 90 \mathrm{~L} \mathrm{~h}^{-1}$ and $120 \mathrm{~L} \mathrm{~h}^{-1}$ by adjusting the air pump. Each test lasted 5 hours with the constant permeate flux of $45 \mathrm{~L} \mathrm{~m}^{-2} \mathrm{~h}^{-1}$ being measured. The hydrodynamics of the four aeration rates in this experiment were investigated. The real time measurement and the microfiltration proceeded simultaneously. Voltage signals reflect the arrival of the Taylor bubble and liquid slug through two probes at the above four aeration rates. The 
relevant hydrodynamics parameters of the slug flow region are listed in Table 1 , where $L_{\mathrm{B}}$ is Taylor bubble length, and $l_{\mathrm{B}}$ is the diameter of the Taylor bubble, $L_{\mathrm{L}}$ is length of liquid slug, $\varepsilon$ is air injection ratio of the pipe. ${ }^{28}$

Table 1 Calculated parameters of slug flow region

\begin{tabular}{lllll}
\hline$Q_{\mathrm{G}}\left(\mathrm{L} \mathrm{h}^{-1}\right)$ & 30 & 60 & 90 & 120 \\
$U_{\mathrm{G}}\left(\mathrm{m} \mathrm{s}^{-1}\right)$ & 0.074 & 0.147 & 0.221 & 0.294 \\
$U_{\mathrm{B}}\left(\mathrm{m} \mathrm{s}^{-1}\right)$ & 0.769 & 0.980 & 1.191 & 1.471 \\
$L_{\mathrm{B}}(\mathrm{m})$ & 0.023 & 0.040 & 0.044 & 0.058 \\
$L_{\mathrm{L}}(\mathrm{m})$ & 0.134 & 0.163 & 0.157 & 0.162 \\
$\varepsilon(\%)$ & 14.8 & 20.5 & 23.8 & 26.3 \\
$l_{\mathrm{B}}\left(10^{-3} \mathrm{~m}\right)$ & 4.0 & 4.8 & 5.2 & 5.4 \\
$\operatorname{Re}$ & 90 & 179 & 269 & 358 \\
$L_{\mathrm{W}}(\mathrm{m})$ & 0.019 & 0.034 & 0.049 & 0.064 \\
$U_{\mathrm{f}}\left(\mathrm{m} \mathrm{s}^{-1}\right)$ & 1.1716 & 1.1557 & 1.1505 & 1.1486 \\
$\delta_{\mathrm{F}}\left(10^{-3} \mathrm{~m}\right)$ & 4.0 & 3.6 & 3.4 & 3.3 \\
$\tau_{\mathrm{f}}\left(10^{-3} \mathrm{~Pa}\right)$ & 5.89 & 6.28 & 6.37 & 6.32 \\
\hline
\end{tabular}

In Table $1, U_{\mathrm{B}}, L_{\mathrm{B}}, L_{\mathrm{L}}$ and $\varepsilon$ can be determined using the data acquisition system. Furthermore $U_{\mathrm{f}}$, $\delta_{\mathrm{F}}, \tau_{\mathrm{f}}, L_{\mathrm{W}}$ and Re can be obtained from the above equations. The diameter of the Taylor bubble can be then calculated: $l_{\mathrm{B}}=12-2 \delta_{\mathrm{F}}$, here, the 12 means the tube inner diameter. ${ }^{25}$

The relevant hydrodynamics parameters of the slug flow can be obtained by applying conductivity technology. It is necessary to understand which hydrodynamic parameters are responsible for the present system. As shown in Table 1, the data acquisition system indicate that when aeration rate increases, the Taylor bubble velocity, length, and void fraction increased linearly, while the length of the liquid slug had no consistency. The calculated parameters also showed that the falling film thickness decreased when the bubble diameter increased. Cui et al. ${ }^{29}$ also point out that when the bubble size increases its shape changes from spherical to ellipsoid and eventually becomes a spherical cap. The secondary flow will form around the bubble of the spherical cap, so disturbance of the fluid can be more intense and the scouring effect on the membrane surface will improve. Table 1 shows that the bubble's diameter will also increase with an increase in the aeration rate, and a larger diameter of Taylor bubble will be effective in reducing membrane fouling. ${ }^{29}$

It would show the velocity and shear stress of the falling film region increased with an elevated aeration rate. Furthermore, the shear stress of the falling film region could reach $6.37 \times 10^{-3} \mathrm{~Pa}$ with the aeration rate of $90 \mathrm{~L} \mathrm{~h}^{-1}$; it did not increase when the aeration rate also increased. The Taylor bubble and liquid slug caused different turbulence intensities. With an increase in the aeration rate, the wake region's flow pattern became irregular, and the liquid slug generally dispersed many small bubbles, which had a smaller diameter and were closer to the wall. This helps to enhance the liquid's turbulence, which in turn improves mass transfer and heat transfer. 
These turbulent movements, associated with small gas bubbles, were to some extent able to dislocate and remove cell debris and particles that had accumulated and partially clogged the pore channels. ${ }^{8}$ Membrane fouling had slowed down. The wake region's length had also increased with an increase in the aeration rate. Li et al. have found that it could significantly decrease concentration polarization and membrane fouling by increasing the wake region's length under slug flow. ${ }^{30}$ The degree of turbulence on the membrane surface mainly related to the Reynolds number. L. Vera et al. have shown that the wake region experienced turbulence when Re was over $90 .^{24}$ The wake region was always in a turbulent state in this system. The hydrodynamic parameters regularly changed with the aeration rate continuously increased (Table 1).

Fig. 4 depicts the plot for transmembrane pressure through time at various aeration rates. The variations in these aeration rates wielded a significant influence on the transmembrane pressure. As shown in Fig. 4, compare to the absence of aeration, aeration have certain effect on slowing membrane fouling. The membrane fouling rate clearly decreased as the aeration rate rose. However, when the aeration rate was over $90 \mathrm{~L} \mathrm{~h}^{-1}$, further increase in the aeration rate had no significant effect on the membrane fouling rate. This is because the cross-flow microfiltration could be divided into two stages, membrane pore plugging and cake layer formation. ${ }^{31}$ As the membrane pore plugging mainly occurred in the initial filtration stage, it was noticeable that the aeration rate did not influence the initial stage (Fig. 4). During this stage the depositing of yeast particles on the membrane surface was definitely the main reason for flux-reducing phenomena.

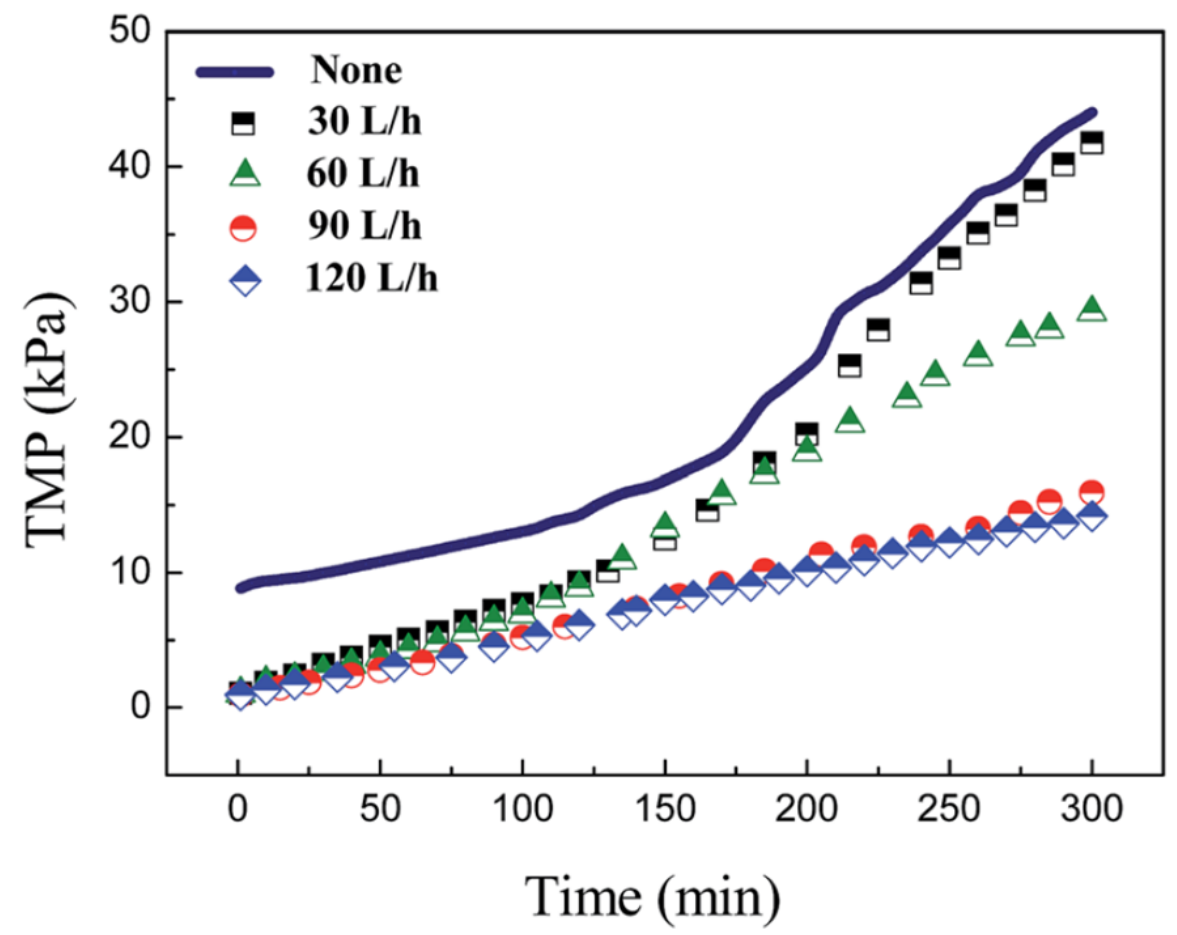

Fig. 4 The behaviors of transmembrane pressure under different aeration rates.

As time passed the cake layer formation could substantially increase filtration resistance. As shown in Fig. 4, the TMP growth rate did not decrease when the aeration rate increased. Shear force also indicated the same trend. This phenomenon could be explained by inertial lift, ${ }^{32,33}$ 
where in the case of large particles and high shear rates, particles reverse diffusion from the membrane surface to the body's liquid under the effect of inertial lift. When the inertial lift rate and the permeate rate offset each other, particles will not be deposited on the surface of the membrane. In the initial of the filtering, permeate rate higher than inertial lift rate, particles will deposited on the surface of the membrane and formed the cake layer. However, after filtering for a while, the cake layer gradually thickens and the resistance continues to increase, which will lead to permeate flux continuing to decline. When the permeate rate and inertial lift rate are in balance, the permeate rate will no longer decrease and the growth rate of TMP will also become more stable.

This study showed that the TMP growth rate did not decrease when the aeration rate increased. It could also be interpreted as meaning that the hydrodynamics of the slug flow produced a thin and densely packed cake layer. Due to the compression effect, the deposit became more consolidated and a continuously rising aeration rate failed to disrupt it. A series of tests suggested that an optimum aeration rate exists at about $90 \mathrm{~L} \mathrm{~h}^{-1}$ for obtaining the minimum growth rate of TMP.

\subsection{Influence of pulsatile air-flow on the growth rate of TMP}

It concluded that increasing the aeration rate could effectively delay membrane fouling in the previous experiment. This is because high gas-velocity in a slug flow could lower the cake layer thickness, but a compression effect was inevitable. A further rise in the aeration rate could not improve the shear stress of the falling film region, which was also proved in the previous experiment. The experiment of Wang et al. ${ }^{17}$ proved that compared with the constant flow, the pulsating flow can increase disturbance in corrugated tube. Thus, in tubular membrane reactor, it would help to slow down the membrane fouling. This part, turning the constant air-flow into periodic pulsatile air-flow, low gas-velocity and high gas-velocity were used for providing different shear forces in filtration. High gas-velocity was used to strip the cake layer and suppress it continuously after the low gas-velocity ran for a period of time. This helped to not only achieve a good filtering outcome but also saved energy compared with traditional constant air-flow or liquid-flow technology. This method could change the normal flow pattern and increase turbulence of the slug flow. Fig. 5 shows that typical voltage signals passed through one probe at different alternate interval durations at the alternate aeration rate was $30 \mathrm{~L} \mathrm{~h}^{-1}$ and $90 \mathrm{~L} \mathrm{~h}^{-1}$ and $60 \mathrm{~L} \mathrm{~h}^{-1}$ and $90 \mathrm{~L} \mathrm{~h}^{-1}$, respectively. The high gas-velocity and low gas-velocity were used intermittently in rectangular-wave pause. According to the results for the effect of constant aeration rate on the TMP in our last test, the optimal aeration rate in a slug-flow was about $90 \mathrm{~L}$ $\mathrm{h}^{-1}$. The effect of alternate aeration rates of two groups on the membrane fouling were investigated in the study. One was $30 \mathrm{~L} \mathrm{~h}^{-1}$ and $90 \mathrm{~L} \mathrm{~h}^{-1}$, the other was $60 \mathrm{~L} \mathrm{~h}^{-1}$ and $90 \mathrm{~L} \mathrm{~h}^{-1}$. Two gas-velocities' alternate interval durations were $1 \mathrm{~s}, 10 \mathrm{~s}, 30 \mathrm{~s}, 60 \mathrm{~s}, 120 \mathrm{~s}$, respectively. The pulsatile air-flow can also be obtained applying a real time measurement.

Fig. 5 indicates the changing trend of voltage signal within $30 \mathrm{~s}$. When the alternate interval duration is $1 \mathrm{~s}$ and $10 \mathrm{~s}$, short alternate interval duration and high fluctuation intensity disturbed the formation of the Taylor bubble compared to the constant air-flow. It could not form stable Taylor bubble. When the alternate interval duration over $30 \mathrm{~s}$, it began to form stable slug flow, however, the duration of interlacing junctions was shorter which compares to the duration of 
stable slug flow (Fig. 5). Table 2 also shows the calculated average shear stress of the falling film region regarding the pulsatile air-flow when the times over $30 \mathrm{~s}$. The shear stress of interlacing junctions was $6.07 \times 10^{-3} \mathrm{~Pa}$ and $6.31 \times 10^{-3} \mathrm{~Pa}$ respectively in two groups. As they did not change obviously, the interlacing junctions is not the key to threshold and the alternate interval duration may have a great influence on the pulsatile air-flow. The fluctuation intensity and convection of the fluid were gradually diminished when alternate interval duration increased from 1 to $120 \mathrm{~s}$. It would be conducive to form stable Taylor bubble and have effect to slow down the membrane fouling.

Table 2 Calculated shear stress of pulsatile air-flow

\begin{tabular}{llllll}
\hline Parameter & Constant air-flow & \multicolumn{3}{c}{ Pulsatile air-flow (times over 30 s) } \\
\hline$Q_{\mathrm{G}}\left(\mathrm{L} \mathrm{h}^{-1}\right)$ & 30 & 60 & 90 & $30-90$ (interlacing junction) & $60-90$ (interlacing junction) \\
$\tau_{\mathrm{f}}\left(10^{-3} \mathrm{~Pa}\right)$ & 5.89 & 6.28 & 6.37 & 6.07 & 6.31 \\
\hline
\end{tabular}
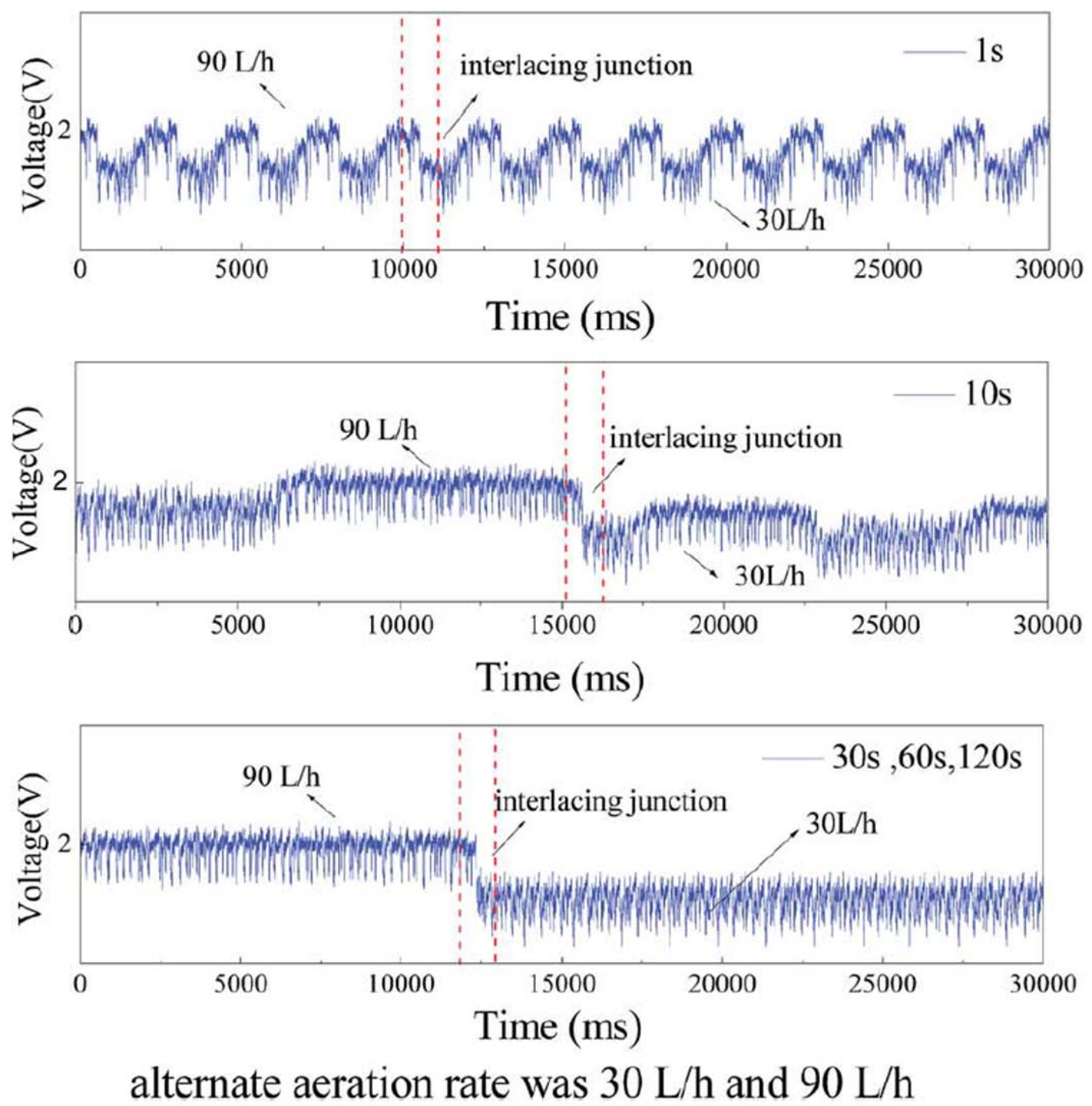

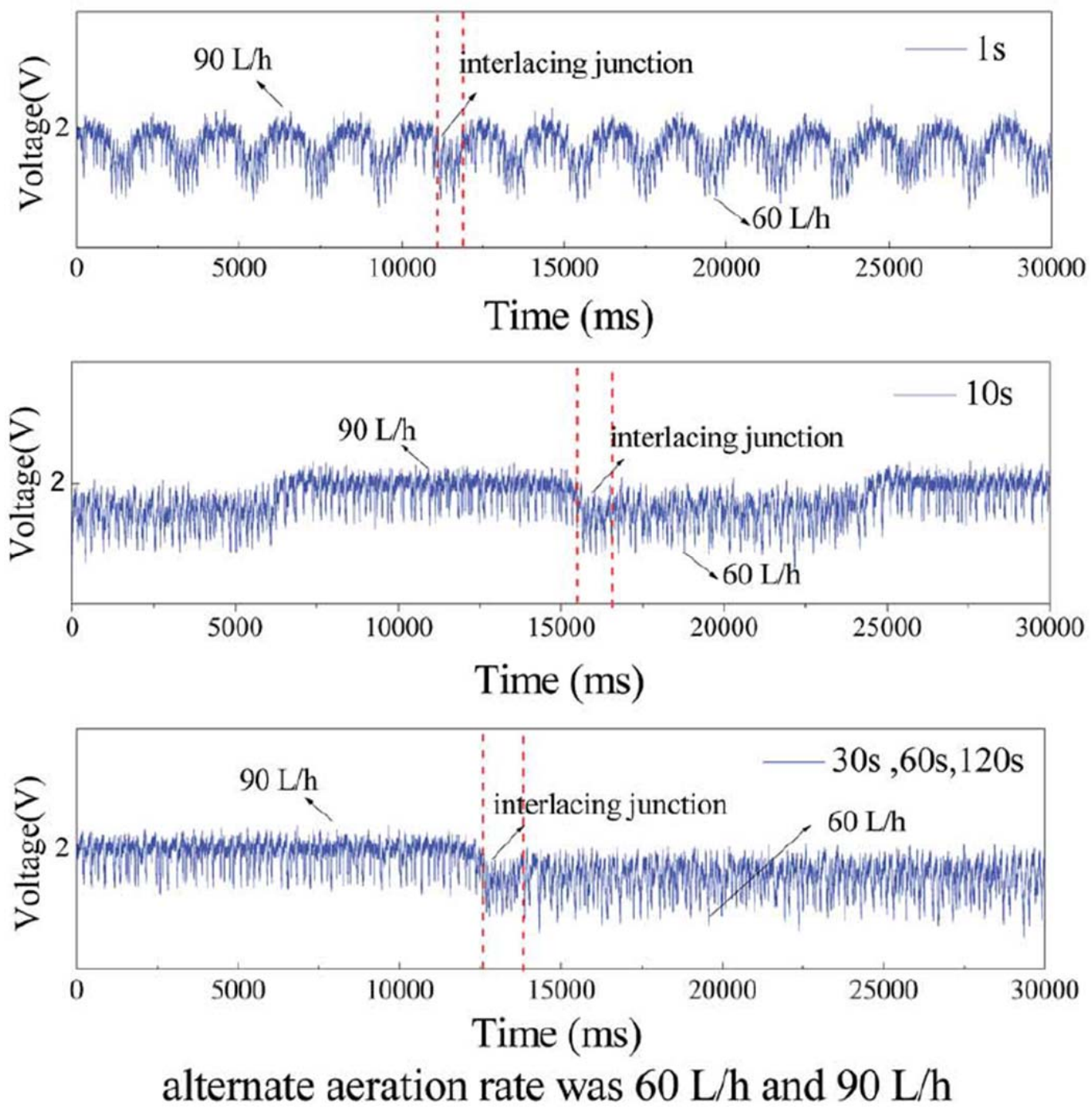

Fig. 5 Typical voltage through one probe at different alternate time durations $(1 \mathrm{~s}, 10 \mathrm{~s}, 30 \mathrm{~s}, 60 \mathrm{~s}$, $120 \mathrm{~s})$.

Cui et al. ${ }^{34}$ applied the force balance equation which combined the body-centered cubic packing model with cake collapse effect. It summarized the falling film velocity played an important role in the cake collapse process. According to the model the cake collapse process could reflect the extent of compression. The high gas-velocity was expected to slow down the cake layer collapse, while a low gas-velocity accelerated the cake layer collapse. However, beyond a certain threshold, this model does not work. In the meantime hope the cake layer was not yet compressed at low gas-velocity in an acceptable period, and high gas-velocity in the next period of time scoured the cake layer, which obstructed the cake layer's formation, and controlled the membrane fouling rate. It could be conclusion that finding a certain threshold of shear force action time to suppress the cake layer has a great significance.

Fig. 6 illustrates a comparison of the TMP's growth rate between different pulsatile air-flow in two groups and constant gas-flow. The dashed and solid horizontal lines represent the growth rates of TMP under the constant gas-flow when the aeration rates are $30 \mathrm{~L} \mathrm{~h}^{-1}, 60 \mathrm{~L} \mathrm{~h}^{-1}$ and $90 \mathrm{~L}$ $\mathrm{h}^{-1}$, which display $8.34 \mathrm{kPa} \mathrm{h}^{-1}, 5.85 \mathrm{kPa} \mathrm{h}^{-1}$ and $3.05 \mathrm{kPa} \mathrm{h}^{-1}$, respectively. As shown in Fig. 6, 
both indicate the same trend in the two bar charts. The TMP's growth rate of pulsatile air-flow gradually decreased as the alternate interval duration increased. When the alternate interval duration was $60 \mathrm{~s}$, the growth rate of TMP was close to $90 \mathrm{~L} \mathrm{~h}^{-1}$, which is the best aeration rate of constant air-flow. When the alternate interval duration rose to $120 \mathrm{~s}$, the growth rate of TMP increased.
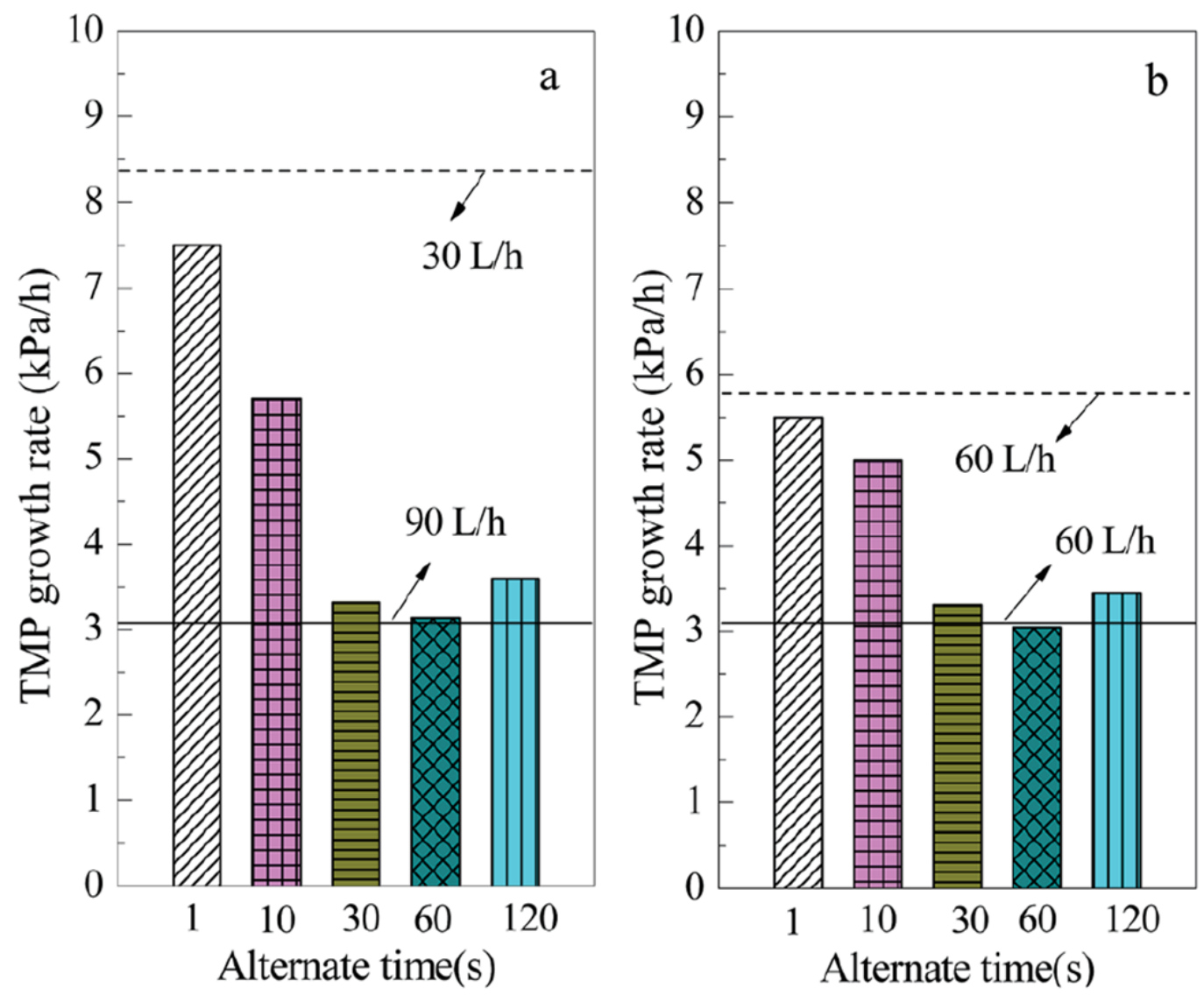

Fig. 6 The growth rate of TMP through alternate time in different alternate gas-velocity of two groups.

Fig. 7 described the effect of gas slug on washing out cake layer within a cycle when the alternate interval duration was $60 \mathrm{~s}$ at the alternate aeration rate was $60 \mathrm{~L} \mathrm{~h}^{-1}$ and $90 \mathrm{~L} \mathrm{~h}^{-1}$. At the start of the filter, the cake layer was relatively loose. For a period of time of operation under low gasvelocity $\left(60 \mathrm{~L} \mathrm{~h}^{-1}\right)$, the cake layer was compressed. However, because of low gas-velocity wields a small shear force in a short period of time, it cannot form a dense cake layer. When the duration was $60 \mathrm{~s}$, the compression of cake layer achieved the greatest degree. Then, the alternate aeration rate was $90 \mathrm{~L} \mathrm{~h}^{-1}$ begun to work. The cake layer was scoured by high shear force, when the high gas-velocity run for a period of time-probably more than $30 \mathrm{~s}$ (this problem will need to be further research) - the cake layer would began to fall off. The complete pulsatile air-flow filtration process has significant effect on slow down the membrane fouling. 


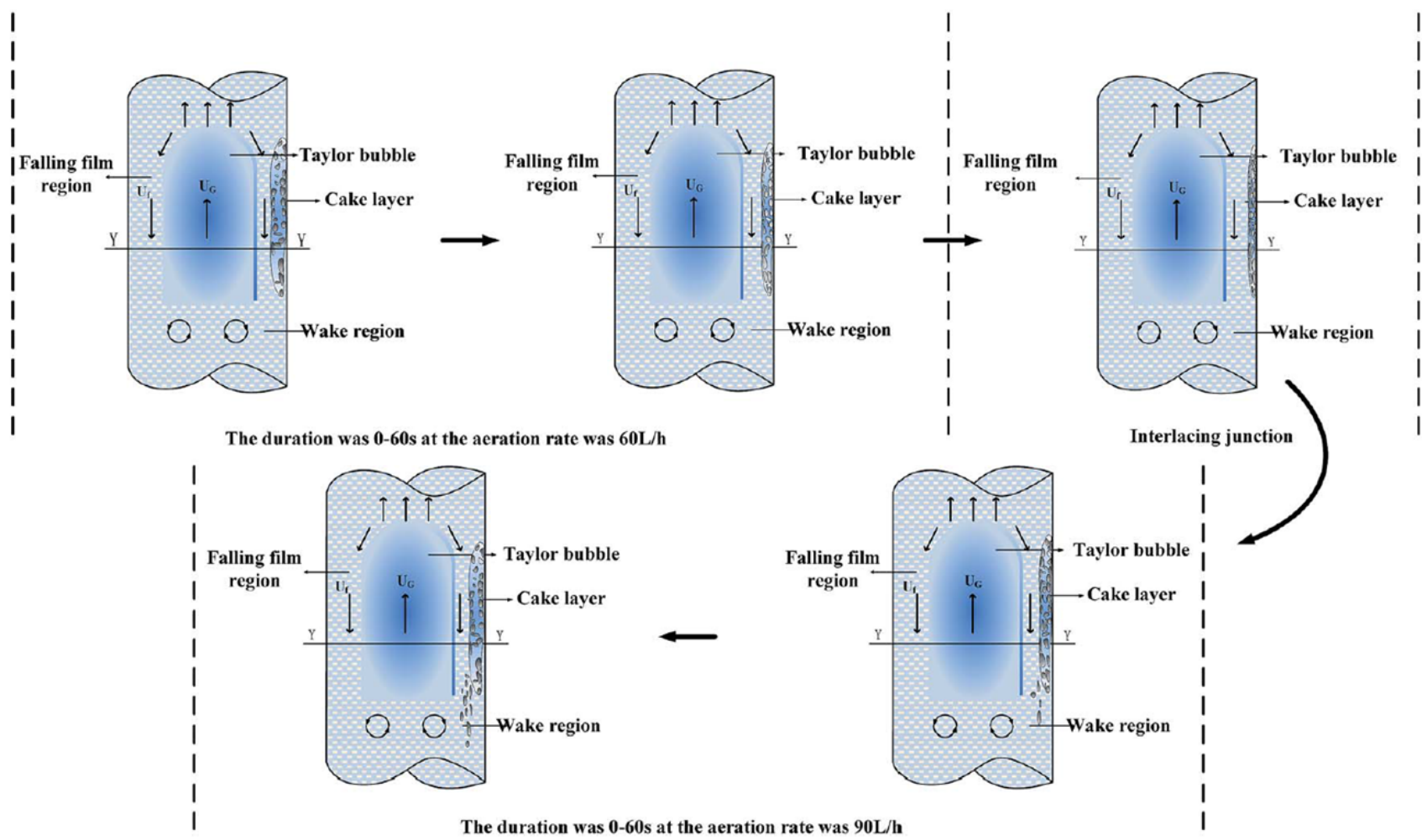

Fig. 7 The effect of gas slug on washing out cake layer within a cycle when the alternate interval duration was $60 \mathrm{~s}$ at the alternate aeration rate was $60 \mathrm{~L} \mathrm{~h}^{-1}$ and $90 \mathrm{~L} \mathrm{~h}^{-1}$.

The pulsatile air-flow-due to the periodic air-flow fluctuations - was conducted in the membrane tube to form a series of complex hydrodynamics, which had disturbed the fluid seriously and affected the slug flow's formation process. Furthermore, the interference of the outermost particles on the cake layer affected the falling film layer. Studies have suggested that the outermost particles on the cake layer are always submerged in the falling film layer. $\frac{10,35}{}$ Meanwhile, the cake layer and concentration polarization on the membrane surface experienced different degrees of scouring with alternate falling film velocity in an acceptable period. The high gas-velocity and low gas-velocity exuded different levels of power in varied alternate interval durations. Low gas-velocity wields a small shear force in a short period of time, due to the lower filtration resistance. It cannot form a dense cake layer. However, beyond a certain threshold of time, the cake layer has been formed due to the influence of the compression effect. High gasvelocity with a high shear force, not only slows down the membrane fouling by scour cake layer and prevents their formation, but also accelerates membrane pore plugging by compressing the cake layer and increasing the filtration resistance. Due to the pulsatile air-flow have different shear force action time. The particle on cake layer was alternately submitted to acting force of different degree in different alternate interval durations. The aggregates were not compressed at all at a low shear force in a certain threshold of time, and the cake layer was scoured by high shear force. Using this method will reduce membrane fouling effectively.

Conversely the high gas-velocity had little effect when it was compressed over a certain threshold.

In the study, shear stress of interlacing junctions did not obviously change and therefore, it may be concluded that interlacing junction had no significant effect on slowing down the TMP growth 
rate. This means that alternate gas-velocity of the two groups is not the key to the threshold, because both indicate the same trend in the two bar charts in Fig. 6. Next, the pulsatile time duration in the two groups was investigated. It clearly shown that when the pulsatile time duration was $60 \mathrm{~s}$, the growth rates of TMP were $3.14 \mathrm{kPa} \mathrm{h}^{-1}$ and $3.04 \mathrm{kPa} \mathrm{h}^{-1}$ respectively, which basically approached to the constant air-flow of $90 \mathrm{~L} \mathrm{~h}^{-1}$, which is the best aeration rate of constant air-flow. However, the membrane fouling rate increased with a further increase in the alternate interval duration. That means when operating with a low gas-velocity beyond an acceptable period, the consolidated cake layer was able to be formed, and high gas-velocity failed to disrupt it. It could conclude the following: firstly, due to the duration of interlacing junctions being short, these junctions had no significant effect on slowing down the TMP growth rate; and secondly, keeping the pulsatile air-flow at $60 \mathrm{~s}$ can effectively delay membrane fouling. The pulsatile air-flow seems to be an effective aeration technique for keeping operating costs down and controlling the growth rate of TMP effectively in the airlift membrane bioreactor.

\subsection{The effect of water outlet position along the membrane tube on membrane fouling}

Fig. 8 represents the relationship between $\triangle \mathrm{TMP}$ and time at each water outlet with an aeration rate of $90 \mathrm{~L} \mathrm{~h}^{-1}$. $\triangle \mathrm{TMP}$ represented the transmembrane pressure which subtracted the initial pressure (gravitational potential energy). Outlet 1 to outlet 4 stands for four water outlets from the bottom to the top. It can be concluded that the two top water outlets were slower than the others regarding their influence on the growth of transmembrane pressure.

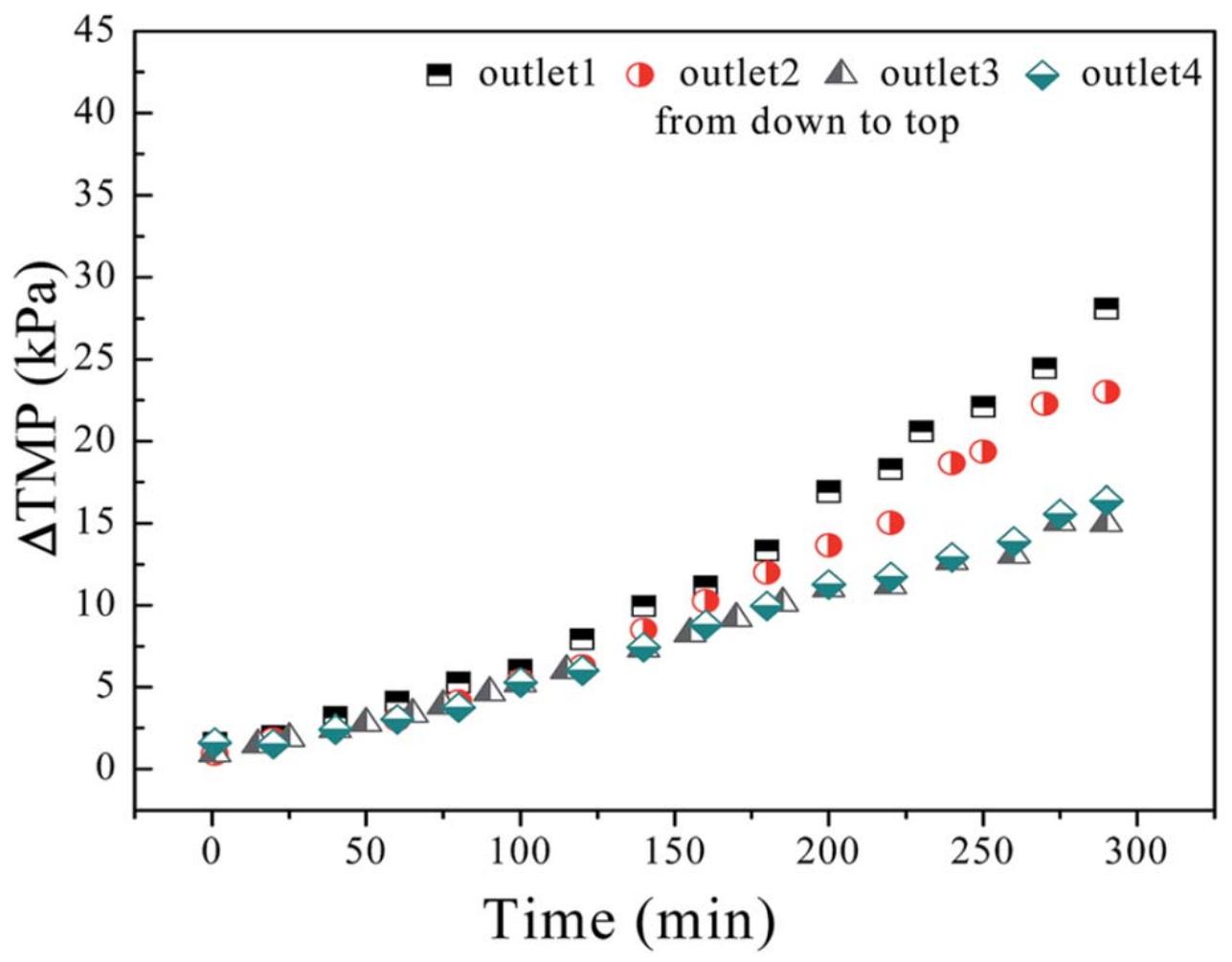

Fig. 8 The behaviors of transmembrane pressure through time at each water outlet. 
The explanation lies in the slug flow being unstable in nature and growing from an incomplete developing stage to a fully developed stage with an increase of tube height before a stable length distribution of liquid slug was finally formed. ${ }^{36}$ Two lower water outlets have not been fully developed. The irregular flow has no effect on scouring the membrane surface, and eventually resulted in an obvious increase in growth rate of TMP. In the study conducted by Fernandes et al., the length of liquid slug was about 8-16 times longer than the inner diameter of the tube, which could be referred to as the fully developed stage slug flow. ${ }^{37}$ Therefore, according to the calculated length of liquid $(0.157 \mathrm{~m})$ at the aeration rate of $90 \mathrm{~L} \mathrm{~h}^{-1}$ as shown in Table 1, it was a fully developed stage slug flow at the measuring position in this study. In other words, two top water outlets are in a fully developed stage. The length of liquid is long enough to absorb falling film so as the thickness of falling film region around the gas slug will weaken while the diameter of the Taylor bubble become larger to make the force of scouring membrane surface increase. Furthermore the liquid slug disperses many small bubbles, which can improve the turbulence of the liquid, leading to the cake layer scouring the membrane surface more effectively.

As another interpretation is that when the top water outlet in the tubular membrane was used, the local permeate flux near the top of the membrane tube would be higher than the bottom under the action of gravity. Additionally the strong gas-water flushing effect acting on the top of the membrane tube delayed the growth of TMP for the whole membrane tube. When the lower water outlet was applied, the local permeate flux at the bottom of the membrane tube was higher than anywhere else. Gas-liquid two-phase flow produced a weaker membrane surface shear stress on the developing stage of the slug flow, leading to the average membrane fouling rate being higher than that when employing the top water outlet. Thus, in order to delay the problem of membrane fouling, it is recommended to use the upper water outlet for the airlift external tubular membrane reactor.

\section{Conclusions}

This paper presented a numerical study to examine the impact of slug flow on microfiltration in an external-loop airlift tubular membrane reactor. Then in order to further save energy and reduce membrane fouling, applied an innovative way - the pulsatile air-flow - to the experiment. The effects of aeration rates, pulsatile air-flow and water outlet positions, were investigated. The following specific conclusions could be drawn from the experimental results:

(1) The relevant hydrodynamics parameters of the slug flow could be obtained by applying conductivity technology. It indicated that when aeration rate increased, the Taylor bubble velocity, length, and void fraction increased linearly, while the length of the liquid slug had no consistency. The calculated parameters also showed that the falling film thickness decreased when the bubble diameter increased.

(2) Membrane fouling was effectively mitigated by increasing gas-velocity to prevent filtered particles from depositing on the membrane surface. The optimal aeration rate at slug flow was around $90 \mathrm{~L} \mathrm{~h}^{-1}$ in this study, and the growth rate of TMP was controlled at $3.05 \mathrm{kPa} \mathrm{h}^{-1}$. However, it had no significant effect on decreasing membrane fouling as the aeration rate continuously increased. 
(3) The growth rate of TMP decreased as alternate interval duration increased from 1 to $120 \mathrm{~s}$. When the alternate interval duration of pulsatile air-flow was $60 \mathrm{~s}$ and the alternate aeration rates were $30 / 90 \mathrm{~L} \mathrm{~h}^{-1}$ and $60 / 90 \mathrm{~L} \mathrm{~h}^{-1}$, this could delay membrane fouling and save a lot of gas compared to adopting constant airflow of $90 \mathrm{~L} \mathrm{~h}^{-1}$. Periodic pulsatile air-flow could provide a different degree of scouring in the falling film, benefiting the alleviation of membrane fouling.

(4) For different water outlet positions along the membrane tube, the membrane fouling gradually slowed down from the bottom to the top in the experiment.

\section{Nomenclature}

$\begin{array}{ll}U_{\mathrm{G}}^{\mathrm{Y}}, U_{\mathrm{L}}^{\mathrm{Y}} & \text { Superficial gas and liquid velocity at cross-section } \mathrm{Y}, \mathrm{m} \mathrm{s}^{-1} \\ U_{\mathrm{B}} & \text { Taylor bubble velocity, } \mathrm{m} \mathrm{s}^{-1} \\ \delta_{\mathrm{F}} & \text { Thickness of falling film region, } \mathrm{m} \\ g & \text { Acceleration due to gravity, } \mathrm{m} \mathrm{s}^{-2} \\ d & \text { Inner diameter of tubular membrane, } \mathrm{m} \\ U_{\mathrm{f}} & \text { Velocity of falling film region, } \mathrm{m} \mathrm{s}^{-1} \\ L_{\mathrm{B}} & \text { Taylor bubble length, } \mathrm{m} \\ L_{\mathrm{W}} & \text { Length of wake region, } \mathrm{m} \\ L_{\mathrm{L}} & \text { Length of liquid slug, } \mathrm{m} \\ l_{\mathrm{B}} & \text { Diameter of Taylor bubble, } \mathrm{m} \\ \mathrm{Re} & \text { The Reynolds number of the wake region of gas slug of fall film } \\ f_{\mathrm{L}} & \text { Friction factor } \\ \rho_{\mathrm{L}} & \text { Liquid density, kg } \mathrm{m}^{-3} \\ u & \text { Kinematic viscosity, } \mathrm{m}^{2} \mathrm{~s}^{-1} \\ \varepsilon & \text { Void fraction of the pipe also called injection ratio } \\ \tau_{\mathrm{f}} & \text { The shear stress in the film flowing around the bubble, Pa }\end{array}$

\section{Acknowledgements}

This work was financially supported by the Chinese National Natural Science Foundation [no. 51678410], Postdoctoral Science Foundation of China [no. 2015M571267] and major R\&D Projects of Tianjin of China [no. 14ZCDGSF00128]. The authors are also grateful for the research collaboration between Tianjin Polytechnic University and University of Technology 
Sydney, especially on the Opening Research Fund of State Key Laboratory of Hollow Fiber Membrane Materials and Processes, 2016.

\section{References}

1. T. Mukai, K. Takimoto, T. Kohno and M. Okada, Water Res., 2000, 34, 902-908.

2. Z. F. Cui, S. Chang and A. G. Fane, J. Membr. Sci., 2003, 221, 1-35.

3. S. Laborie, C. Cabassud, L. Durand-Bourlier and J. M. Laine, Desalination, 1998, 118, 189196.

4. M. Mercier, C. Lagane and C. Fonade, J. Membr. Sci., 2000, 180, 93-102.

5. A. Sofia, W. J. Ng and S. L. Ong, Desalination, 2004, 160, 67-74.

6. F. Yang, A. Bick, S. Shandalov and G. Oron, Water Sci. Technol., 2006, 54, 155-162.

7. A. Fouladitajar, F. Zokaee Ashtiani, H. Rezaei, A. Haghmoradi and A. Kargari, J. Ind. Eng. Chem., 2014, 20, 624-632.

8. M. Mercier, C. Fonade and C. Lafforgue-Delorme, J. Membr. Sci., 1997, 128, 103-113.

9. Q. Y. Li, R. Ghosh, S. R. Bellara, Z. F. Cui and D. S. Pepper, Sep. Purif. Technol., 1998, 14, 79-83.

10. L. Vera, R. Villarroel, S. Delgado and S. Elmaleh, J. Membr. Sci., 2000, 165, 47-57.

11. F. Zhang, W. H. Jing, W. H. Xing and N. P. Xu, Chem. Eng. Sci., 2009, 160, 2859-2865.

12. P. Mikulasek, J. Cakl, P. Pospisil and P. Dolecek, Chem. Biochem. Eng. Q., 2000, 14, $117-$ 123.

13. Y. Wibisono, E. R. Cornelissen and A. J. B. Kemperman, J. Membr. Sci., 2014, 453, 566602.

14. R. Badrnezhad and B. Mirza, J. Ind. Eng. Chem., 2014, 20, 528-543.

15. A. O. Morgado, J. M. Miranda, J. D. P. Araujo and J. B. L. M. Campos, Int. J. Multiphase Flow, 2016, 85, 348-368.

16. C. Cabassud, S. Laborie and J. M. Laine, J. Membr. Sci., 1997, 128, 93-101.

17. W. Wang, J. Y. Yu and X. Yang, J. Wuhan Inst. Technol., 2010, 32, 89-91.

18. R. Collins, F. F. De Moraes and J. F. Davidson, J. Fluid Mech., 1978, 89, 497-514.

19. K. H. Bendiksen, Int. J. Multiphase Flow, 1985, 11, 797-812.

20. F. Zhang, W. H. Jing and W. H. Xing, Ind. Eng. Chem. Res., 2009, 48, 10637-10642.

21. R. Ghosh and Z. F. Cui, J. Membr. Sci., 1999, 162, 91-102.

22. J. M. Kay and R. M. Nedderman, An Introduction to Fluid Mechanics and Heat Transfer: With Applications in Chemical and Mechanical Process Engineering, Cambridge University Press, Cambridge, 1985, pp. 501-504.

23. J. B. L. M. Campos and J. R. F. Guedes De Carvalho, J. Fluid Mech., 1988, 196, 27-37.

24. L. Vera, S. Delgado and S. Elmaleh, Chem. Eng. Sci., 2000, 55, 3419-3428.

25. X. Y. Li and Z. J. Yu, Chem. Eng., 2006, 9, 19-23.

26. J. Wang, Z. Cui, H. Jia and H. W. Zhang, Desalination, 2014, 337, 98-108. 
27. B. S. Gupta, S. Hasan, M. A. Hashim and Z. F. Cui, Bioprocess Biosyst. Eng., 2005, 27, 407413.

28. F. Zhang, W. H. Jing and W. H. Xing, Ind. Eng. Chem. Res., 2009, 48, 10637-10642.

29. Z. F. Cui, S. Chang and A. G. Fane, J. Membr. Sci., 2003, 221, 1-35.

30. Q. Y. Li, Z. F. Cui and D. S. Pepper, Chem. Eng. J., 1997, 67, 71-75.

31. P. Pospisil, R. J. Wakeman and I. O. A. Hodgson, Chem. Eng. J., 2004, 97, 257-263.

32. C. Wisniewski, A. Grasmick and A. L. Cruz, J. Membr. Sci., 2000, 178, 141-150.

33. T. Carroll and N. A. Booker, J. Membr. Sci., 2000, 168, 203-212.

34. T. Taha and Z. F. Cui, Chem. Eng. Sci., 2006, 61, 676-687.

35. D. Barnea and N. Brauner, Int. J. Multiphase Flow, 1985, 11, 43-49.

36. H. M. Zhang, J. F. Gao, T. Jiang, D. W. Gao, S. R. Zhang, H. Y. Li and F. L. Yang, Bioresour. Technol., 2011, 102, 11121-11131.

37. F. C. Fernandes, R. Semiat and A. E. Dukler, AIChE J., 1983, 29, 981-989. 